University of Wollongong

Research Online

Australian Institute for Innovative Materials -

Papers

Australian Institute for Innovative Materials

$1-1-2017$

Multiple Stimuli-Responsive Fluorescence Behavior of Novel Polyamic Acid Bearing Oligoaniline, Triphenylamine, and Fluorene Groups

Ying Yan

Jilin University

Ningwei Sun

Jilin University

Fangfei Li

Jilin University

Xiaoteng Jia

University of Wollongong, xj916@uowmail.edu.au

Ce Wang

Jilin University

See next page for additional authors

Follow this and additional works at: https://ro.uow.edu.au/aiimpapers

Part of the Engineering Commons, and the Physical Sciences and Mathematics Commons

Research Online is the open access institutional repository for the University of Wollongong. For further information contact the UOW Library: research-pubs@uow.edu.au 


\title{
Multiple Stimuli-Responsive Fluorescence Behavior of Novel Polyamic Acid Bearing Oligoaniline, Triphenylamine, and Fluorene Groups
}

\author{
Abstract \\ Multiple stimuli-responsive fluorescent materials have gained increasing attention for their fundamental \\ investigation and intelligent applications. In this work, we report design and synthesis of a novel polyamic \\ acid bearing oligoaniline, triphenylamine, and fluorene groups, which served as sensitive units and \\ fluorescence emission unit, respectively. The resulting polymer exhibits multiple stimuli-responsive \\ fluorescence switching behavior triggered by redox species, $\mathrm{pH}$, electrochemical, and pressure stimuli. \\ Every fluorescence switching mechanism upon each stimulus was studied in detail. The interactions and \\ energy transfer between sensitive units and emission unit are largely responsible for this fascinating \\ fluorescent switching behavior. This work provides a deep understanding of the optical switching essence \\ upon these stimuli, opening the way for the development of new fluorescent sensing applications.

\section{Disciplines} \\ Engineering | Physical Sciences and Mathematics

\section{Publication Details} \\ Yan, Y., Sun, N., Li, F., Jia, X., Wang, C. \& Chao, D. (2017). Multiple Stimuli-Responsive Fluorescence \\ Behavior of Novel Polyamic Acid Bearing Oligoaniline, Triphenylamine, and Fluorene Groups. ACS Applied \\ Materials and Interfaces, 9 (7), 6497-6503.

\section{Authors} \\ Ying Yan, Ningwei Sun, Fangfei Li, Xiaoteng Jia, Ce Wang, and Danming Chao
}




\section{Multiple Stimuli-Responsive Fluorescence Behavior}

\section{of Novel Polyamic Acid bearing Oligoaniline,}

\section{Triphenylamine and Fluorene Groups}

Ying Yan ${ }^{a}$, Ningwei Sun ${ }^{a}$, Fangfei $\mathrm{Li}^{b}$, Xiaoteng Jia ${ }^{c}$, Ce Wang ${ }^{a}$, Danming Chao ${ }^{a, *}$

${ }^{a}$ Alan G. MacDiarmid Institute, College of Chemistry, Jilin University, Changchun, 130012, P.R.

China. E-mail: chaodanming@jlu.edu.cn (D Chao), Tel.: +86-431-85168292; Fax: +86-43185168292.

${ }^{\mathrm{b}}$ State Key Lab of Superhard Materials, Jilin University, Changchun 130012, P.R. China.

${ }^{c}$ Intelligent Polymer Research Institute, AIIM Faculty, University of Wollongong, Wollongong, NSW 2522, Australia.

ABSTRACT: Multiple stimuli-responsive fluorescent materials have gain increasing attention for their fundamental investigation and intelligent applications. In this work, we report design and synthesis of a novel polyamic acid bearing oligoaniline, triphenylamine and fluorene groups, served as sensitive units and fluorescence emission unit, respectively. The resulting polymer exhibits multiple stimuli-responsive fluorescence switching behavior triggered by redox species, $\mathrm{pH}$, electrochemical and pressure stimuli. Every fluorescence switching mechanism upon each stimulus has been studied in detail. The interactions and energy transfer between sensitive units 
and emission unit are largely responsible for this fascinating fluorescent switching behavior. This work provides a deep understanding of the optical switching essence upon these stimuli, opening the way for the development of new fluorescent sensing applications.

KEYWORDS: oligoaniline, triphenylamine, stimuli-responsive, fluorescence switching, electrochromism

\section{INTRODUCTION}

Stimuli-responsive fluorescent materials have gained much exposure in recent years due to their potential applications as sensors, bioimaging, memory media and displays. ${ }^{1-7}$ Chemical substances, ${ }^{89}$ temperature, ${ }^{10}$ light, ${ }^{11} \mathrm{pH},{ }^{12}$ electricity ${ }^{13}$ and mechanical force ${ }^{14}$ are the typical stimuli utilized to change the fluorescent behaviors of these materials. To explore the mechanism of fluorescent switching and impart more functionality, many multiple stimuli-responsive fluorescent materials have been reported. ${ }^{15-18}$ For example, Huang et al. ${ }^{15}$ have designed and synthesized two kind of multiple stimuli-responsive fluorescent gels based on cholesterol containing benzothiazole fluorophore, which is sensitive to temperature, solvent, ultrasound and

mercury ions. Yan et al. ${ }^{16}$ have reported a mechanical-induced and solvent stimuli-responsive fluorescent change by assembling niflumic acid into the interlayer region of $\mathrm{Zn}-\mathrm{Al}$ layered double hydroxides. Although great efforts have recently been made to prepare multiple stimuliresponsive fluorescent materials, it still a challenge to reveal the fluorescent switching behavior. One promising approach to obtain multiple stimuli-responsive fluorescent materials is the incorporation of fluorophore and sensitive groups into the polymer backbone.

Oligoanilines, as the model compounds of polyaniline, have received much attention due to their well-defined structure, good electro-optical properties and high sensitivity to redox 
substances, $\mathrm{pH}$ and electricity. ${ }^{19}$ In recent works, we have shown a fluorescent regulation and switching can be achieved by the introduction of oligoanilines and fluorophores into the molecular structure. ${ }^{9,20,21}$ In this system, some stimuli could alter the electronic energy level structure of oligoanilines readily and/or eliminate the pathway of fluorescence quenching. This will influence the fluorescent behavior of fluorophores through the intermolecular action between oligoaniline and fluorophore. Triphenylamine derivatives have demonstrated promise in dye-sensitized solar cells, organic light emitting diodes, memories and electrochromic devices. ${ }^{22-}$ 29 These attractive applications and characteristics are ascribed to the lone pair electrons variation of the nitrogen atom, which are also the sensitive unit to $\mathrm{H}^{+}$and electricity. Recently, much attention has been made to synthesize fluorescent responsive polymers bearing triphenylamine groups. ${ }^{30}$ Their interesting electro-optical properties, such as electrofluorescene and electrochromism, have been revealed and studied in detail.

Herein, we have synthesized a new polyamic acid bearing oligoaniline, triphenylamine and fluorene groups (PAAOTF). Its multiple stimuli-responsive spectroscopic behavior, upon redox species, $\mathrm{pH}$, electricity and pressure, has been disclosed and investigated. In this fluorescent switching system, oligoaniline and triphenylamine serve as the sensitive units, while fluorene is responsible for fluorescence emission unit.

\section{EXPERIMENTAL SECTION}

\section{Materials and Instrumentation.}

All chemicals used in this work were purchased from commercial sources and used as received without further purification. Electroactive tetraaniline-containing diamine (EDA) and 
$N, N$-di(4-aminophenyl)-2-amino-9,9-dimethylfuorene were synthesized in our lab according to the procedures described in the literatures..$^{31,32}$

Nuclear magnetic resonance (NMR) spectra were run on a Bruker-500 spectrometer using deuterated dimethyl sulfoxide. Fourier-transform infrared spectra (FTIR) were recorded on a BRUKER VECTOR 22 Spectrometer in the range of $4000-400 \mathrm{~cm}^{-1}$. The molecular weight information of PAAOTF was determined on Shimadzu Gel permeation chromatography (GPC) unit equipped with a Shimadzu GPC-802D gel column and SPD-M10AVP detector. Its thermal properties were studied on PerkineElmer PYRIS 1 TGA in the temperature range of $100-720^{\circ} \mathrm{C}$ under air atmosphere. Measurement of glass transition temperature was carried out using differential scanning calorimetric (DSC) analysis on a TA instrument DSC Q100 with a scanning rate of $10{ }^{\circ} \mathrm{C} / \mathrm{min}$ under a nitrogen flow. Cyclic voltammetry (CV) of PAAOTF was performed on a CHI 660A Electrochemical Workstation (CH Instruments, USA) with a conventional threeelectrode cell in $0.1 \mathrm{M}$ tetrabutylammonium perchlorate (TBAP) $\mathrm{CH}_{3} \mathrm{CN}$ solution. UV-vis spectra were collected using UV-2501 PC Spectrometer (SHIMADZU). Photoluminescence (PL) spectra were performed on RF-5301 PC Spectrometer (SHIMADZU).

Spectroelectrochemical experiments and spectrochronoamperometry, constructed by combining the Electrochemical Workstation and UV-vis spectrometer/Fluorescence spectrometer, were used to investigate the electrochromic/electrofluorescent behavior of PAAOTF. The conventional three electrode cell was employed in $0.1 \mathrm{M} \mathrm{TBAP} \mathrm{CH}_{3} \mathrm{CN}$ solution, using $\mathrm{Ag} / \mathrm{AgCl}$ electrode as the reference electrode, a platinum wire electrode as the counter electrode, and PAAOTF/ITO as the working electrode, respectively.

High-pressure experiments were conducted in a symmetric diamond anvil cell (DAC) with a large conical opening aperture. ${ }^{33}$ A piece of PAAOTF film was enclosed into the chamber with 
silicon oil as the pressure transmission medium, and ruby chip for in situ pressure calibration. High pressure UV-vis absorption spectra were measured on Ocean Optics QE65000 spectrophotometer. Photoluminescence measurements under high pressure were accomplished on Acton SpectraPro 500i spectrometer with a liquid nitrogen-cooled CCD detector (Princeton Instruments) and $325 \mathrm{~nm}$ excitation source.

\section{Synthesis of PAAOTF}

A mixture of 1,2,4,5-cyclohexanetetracarboxylic dianhydride (0.336 g, $1.5 \mathrm{mmol})$, EDA (0.205 g, $0.3 \mathrm{mmol}), N, N$-di(4-aminophenyl)-2-amino-9,9-dimethylfuorene (0.470 g, $1.2 \mathrm{mmol})$ and $5 \mathrm{~mL} N$-methyl-2-pyrrolidinone (NMP) was added into $50 \mathrm{~mL}$ three-necked round-bottom flask under argon atmosphere. The reaction proceeded with magnetic stirring at room temperature for $24 \mathrm{~h}$. The resulting PAAOTF NMP solution was placed in the freezer at $5^{\circ} \mathrm{C}$. Some PAAOTF powder was obtained using precipitation method with water and ethanol. Characterization of PAAOTF: ${ }^{1} \mathrm{H}$ NMR (d $\mathrm{d}_{6}$-DMSO): $\delta=12.0 \mathrm{ppm}(10 \mathrm{H},-\mathrm{COOH}), \delta=10.20 \mathrm{ppm}$ (1H, -CONH- in EDA), 9.59 ppm $(10 \mathrm{H},-\mathrm{CONH}-$ in the main chain $), \delta=7.46-7.87 \mathrm{ppm}(3 \mathrm{H}$, NH- $), \delta=7.51-6.53 \mathrm{ppm}(\mathrm{mH}, \mathrm{Ar}-\mathrm{H}), \delta=2.82 \mathrm{ppm}(20 \mathrm{H},>\mathrm{CH}-) \delta=2.12 \mathrm{ppm}\left(20 \mathrm{H},-\mathrm{CH}_{2^{-}}\right), \delta$

$=1.25 \mathrm{ppm}\left(24 \mathrm{H},-\mathrm{CH}_{3}\right)$. FTIR $\left(\mathrm{KBr}, \mathrm{cm}^{-1}\right): 3388\left(\mathrm{v}_{\mathrm{N}-\mathrm{H}}\right), 3039\left(\mathrm{v}_{\mathrm{C}-\mathrm{H}}\right.$ of aryl groups), 2956 and $2923\left(v_{\mathrm{C}-\mathrm{H}}\right.$ of alkyl groups), $1681\left(v_{\mathrm{C}=\mathrm{O}}\right), 1601$ and $1506\left(v_{\mathrm{C}=\mathrm{C}}\right.$ of benzenoid rings $), 1304\left(v_{\mathrm{C}-\mathrm{N}}\right)$, $1234\left(v_{\mathrm{C}-\mathrm{O}-\mathrm{C}}\right), 827\left(\delta_{\mathrm{C}-\mathrm{H}}\right), 737\left(\delta_{\mathrm{C}-\mathrm{H}}\right) . \mathrm{GPC}$ data: Mw: 51820, PDI: 1.88.

\section{RESULTS AND DISCUSSION}




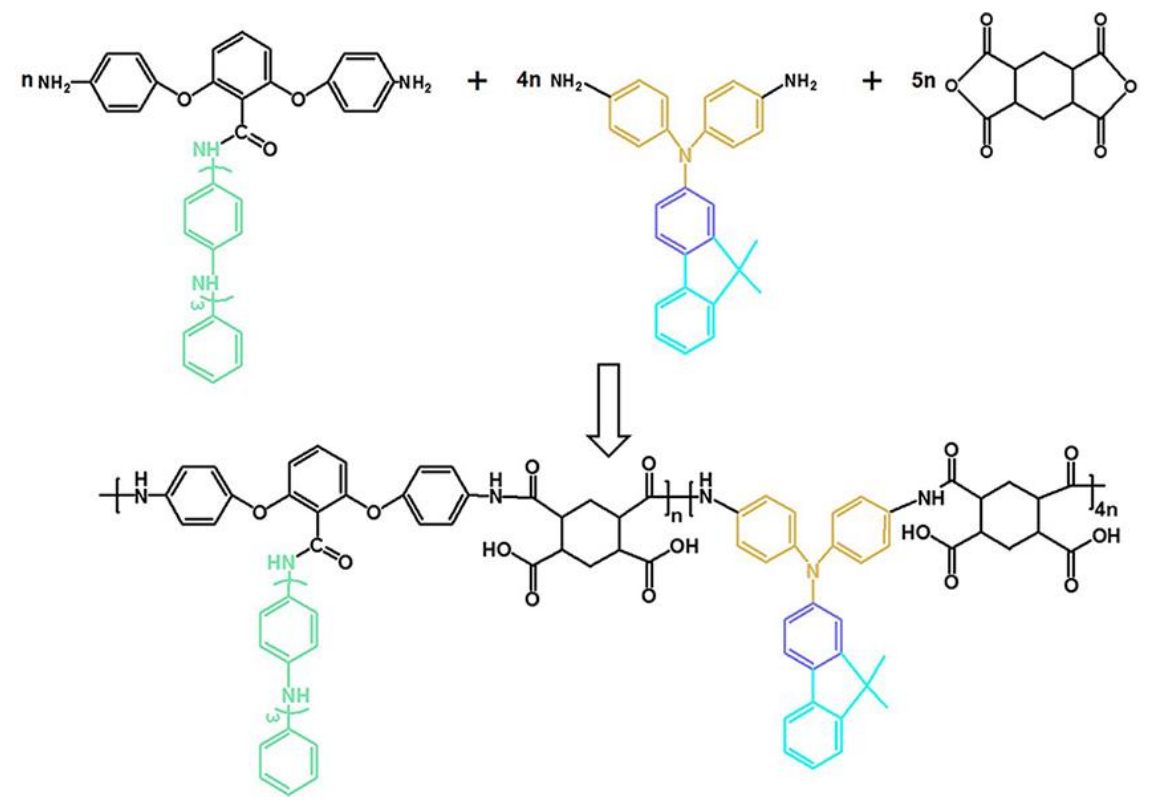

Scheme 1. Synthetic route of the novel polyamic acid bearing oligoaniline, triphenylamine and fluorene groups.

Scheme 1 shows the synthetic route of the novel polyamic acid prepared by nucleophilic copolymerization of electroactive tetraaniline-containing diamine, $N, N$-di(4-aminophenyl)-2amino-9,9-dimethylfuorene and 1,2,4,5-cyclohexanetetracarboxylic dianhydride. The ratio of triphenylamine to tetraaniline in the molecular structure of PAAOTF was fix at 4, which was determined according to their intrinsic optical characteristics. The structure of PAAOTF was confirmed via FTIR, ${ }^{1} \mathrm{H}$ NMR, and GPC (Figure S1 and S2). The FTIR spectrum of PAAOTF shows the characteristic absorption bonds around $3388 \mathrm{~cm}^{-1}$ corresponding to the $\mathrm{N}-\mathrm{H}$ stretching vibration, around $3039 \mathrm{~cm}^{-1}$ and $2956 \mathrm{~cm}^{-1}$ due to the $\mathrm{C}-\mathrm{H}$ stretching vibrations of aryl and alkyl groups. The vibration around $1681 \mathrm{~cm}^{-1}$ is attributed to the stretching vibration of carbonyl groups. The stretching vibration of $\mathrm{C}=\mathrm{C}$ groups in the benzene rings is observed at $1601 \mathrm{~cm}^{-1}$ and $1506 \mathrm{~cm}^{-1}$. The characteristic stretching vibration of $\mathrm{C}-\mathrm{N}$ appears at $1304 \mathrm{~cm}^{-1}$. The deformation vibration of PAAOTF is presented at $827 \mathrm{~cm}^{-1}$, and $737 \mathrm{~cm}^{-1}$. The ${ }^{1} \mathrm{H}$ NMR 
spectrum exhibits characteristic signals at $10.20 \mathrm{ppm}$ and $9.59 \mathrm{ppm}$, ascribed to the amide groups from EDA and backbone. The signal of carboxylic acid is found around $12.00 \mathrm{ppm}$. The signals at $2.82 \mathrm{ppm}, 2.12 \mathrm{ppm}$ and $1.25 \mathrm{ppm}$ are due to the methyne, methylene and methyl groups, respectively. Moreover, the ratio of two functional units in the polymer was confirmed by the integral ratio of $\mathrm{H}$ atoms. Its molecular weight information also suggests the success of the polymerization reaction. In the thermal evaluation, PAAOTF shows good thermostability with a high degradation temperature $\left(340^{\circ} \mathrm{C}\right)$. Further, the polyimide derived from PAAOTF revealed a high glass transition temperature at $304^{\circ} \mathrm{C}$ measured by DSC analysis. Moreover, PAAOTF is soluble in a variety of organic polar solvents including dimethylformamide (DMF), dimethyl acetamide (DMAc), dimethyl sulfoxide (DMSO), and NMP, due to the bulky pendants in the molecular architecture. Flexible free-standing PAAOTF film was also prepared readily by the drop-casting method. Considering its easy synthesis, good thermostability, high solubility, and expected film-forming ability, PAAOTF could be attractive in a number of advanced applications.

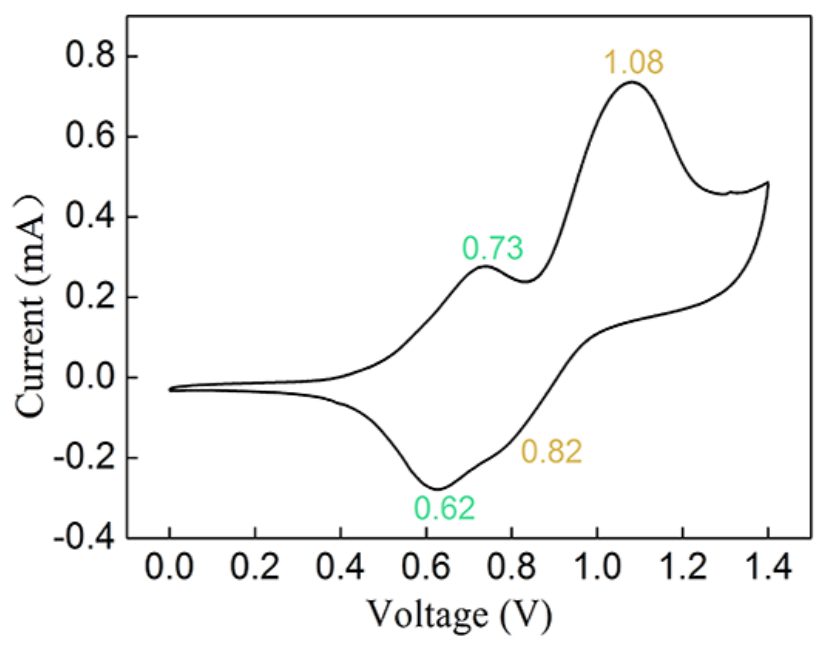

Figure 1. Cyclic voltammogram of PAAOTF electrode in $\mathrm{CH}_{3} \mathrm{CN}$ with $0.1 \mathrm{M}$ TBAP at a scan rate of $100 \mathrm{mV} \mathrm{s}^{-1}$. 
We next evaluated the electrochemical behavior of PAAOTF by cyclic voltammetry (CV) in $0.1 \mathrm{M}$ TBAP $\mathrm{CH}_{3} \mathrm{CN}$ solution with traditional three-electrode system. The PAAOTF/ITO working electrode was fabricated by spin coating method using its corresponding filtered NMP solution. The thickness of PAAOTF film was about $250 \mathrm{~nm}$ measured by profilometer. As shown in Figure 1, the CV curve exhibited two pairs of redox peaks centered at $0.73 \mathrm{~V} / 0.62 \mathrm{~V}$ and 1.08 $\mathrm{V} / 0.82 \mathrm{~V}$, which are respectively assigned to the reductive state/oxidative state transition of oligoaniline segments and neutral state/radical cation state transition in the nitrogen atom of triphenylamine segments. Different from the previous reports about electrochemical behavior of polyaniline and its derivatives, ${ }^{31}$ the oligoaniline segments in PAAOTF exhibited only one pair of redox peaks in the range of $0-0.8 \mathrm{~V}$ in this organic electrolyte system. Due to its high stability and good adhesion on the ITO substrate, the PAAOTF layer exhibited excellent reversibility of electroactivity characteristics for cycles between 0 and $1.4 \mathrm{~V}$, which is of great benefit in electrooptical switching system.
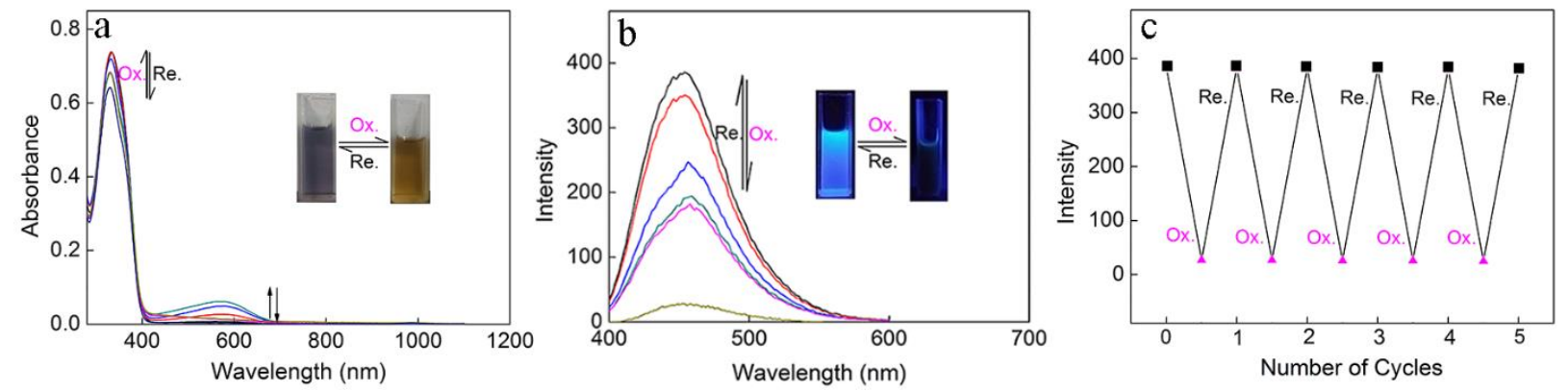

Figure 2. (a) UV-vis spectrum and (b) fluorescence switching of PAAOTF NMP solution as it is oxidized and/or reduced using ammonium persulfate/phenylhydrazine; Inset shows optical and fluorescent images of PAAOTF solution under redox species; (c) approximate reversible fluorescence on-off cycles of PAAOTF solution under redox species. The excitation wavelength is $385 \mathrm{~nm}$. 
The spectroscopic characteristics of PAAOTF with redox stimuli were studied in detail by UV-vis absorption spectra and fluorescence emission spectra. In this redox stimuli-responsive cycles, ammonium persulfate and phenylhydrazine were chosen as the redox species. Firstly, one absorption peak at $333 \mathrm{~nm}$ was observed before the oxidation (Figure 2a), which is ascribed to $\pi$ $\pi *$ transitions in the benzoid rings. ${ }^{34,35}$ After addition of quantitative ammonium persulfate as an oxidant, a slight blue-shift and intensity decrease of the absorption peak at $333 \mathrm{~nm}$ was observed. Meanwhile, a new absorption peak at $575 \mathrm{~nm}$ appeared, ascribed to the exciton-type transition between the HOMO orbital of the benzoid ring and the LUMO orbital of the quinoid ring in the oligoaniline segments. ${ }^{34,35}$ The intensity of exciton-type absorption peak firstly increased and then decreased during the oxidation process. Moreover, the color of PAAOTF solution changed from darkslateblue to sienna (Inset of Figure 2a). As shown in the fluorescence spectra (Figure $2 \mathrm{~b}$ ), one emission peak, originated from the fluorene groups, appeared at $453 \mathrm{~nm}$. During the oxidation process, the fluorescence intensity of PAAOTF solution underwent a gradual decrease from its reductive state to oxidative state, finally reduced to $7 \%$ of its original value. Their corresponding fluorescence images were also presented in the Figure $2 \mathrm{~b}$. Furthermore, no obvious shift was found for this emission peak during the oxidation process. The entire oxidation process continued for about $3 \mathrm{~h}$. The oligoaniline group reacts more easily with oxidative chemicals as compared to triphenylamine groupsdue to its low oxidative potential. ${ }^{31}$ Moreover, the quantitative addition would also ensure that the oxidative chemicals only reacted with oligoanilines, but the triphenylamine groups will not engaged in the redox reaction. Considering the reversible redox properties of oligoanilines, the spectroscopic properties of PAAOTF should be recoverable by adding a reductant. As expected, phenylhydrazine was utilized to revert spectroscopic properties of PAAOTF successfully. The approximate reversible fluorescence on- 
off cycles of PAAOTF solution was achieved easily through the alternative addition of redox species (Figure 2c). Here, a reasonable mechanism for fluorescence switching by redox stimuli was proposed by virtue of the molecular transition of oligoanilines upon the redox action. When the oligoanilines were oxidized, the quinoid rings appeared in the molecular structure, which would acted as excitation traps and quench the fluorescence ${ }^{20}$, resulting in the 'off' state. After addition of reductant, the quinoid rings were eliminated gradually, the non-radiative decay pathway weaken, and then the fluorescence recovered, resulting in the 'on' state.
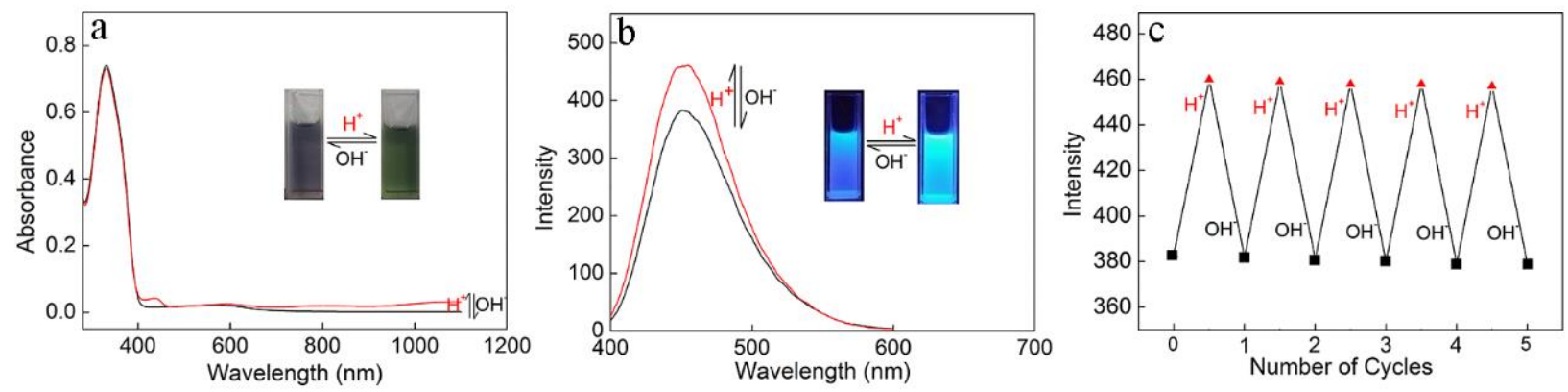

Figure 3. (a) UV-vis spectrum and (b) fluorescence switching of PAAOTF NMP solution as it is altered using $\mathrm{HCl}$ and/or $\mathrm{NaOH}$ solutions; Inset shows optical and fluorescent images of PAAOTF solution under different $\mathrm{pH}$; (c) approximate reversible fluorescence on-off cycles of PAAOTF solution using $\mathrm{HCl}$ and $\mathrm{NaOH}$ solutions. The excitation wavelength is $385 \mathrm{~nm}$.

In view of the alkaline essence of multiple amine groups in the molecular architecture, the $\mathrm{H}^{+} / \mathrm{OH}^{-}$ions could be another stimuli for the spectroscopic switching of PAAOTF due to the protonation and/or deprotonation. Detailed information about its spectroscopic switching characteristics upon $\mathrm{pH}$ values was obtained through the UV-vis spectrum and fluorescence emission spectrum as shown in Figure 3. After adding $2 \mu \mathrm{L} 1.0 \mathrm{M} \mathrm{HCl}$ solution into the PAAOTF solution (stirring for $10 \mathrm{~s}$ ), we found that the resulting PAAOTF solution changed from darkorchid to green (Inset of Figure 3a). And some absorption around $420 \mathrm{~nm}$ and in range 
of 650 - $1100 \mathrm{~nm}$ has also been observed in the UV-vis absorption curve. As for its fluorescence behavior, the fluorescent intensity enhanced to $120 \%$ of its initial value (Figure 3b). More bright fluorescence image after addition of $\mathrm{HCl}$ solution was presented as the inset of Figure $3 \mathrm{~b}$. Similarly, the spectroscopic properties of PAAOTF solution should be recoverable by adding an alkaline substance. As expected, the spectroscopic properties of PAAOTF solution reverted to its original state successfully by adding $2.5 \mu \mathrm{L} 1.0 \mathrm{M} \mathrm{NaOH}$ solution. Finally, in accordance with the above approach, the approximate reversible fluorescence on-off cycles of PAAOTF solution was achieved readily (Figure 3c). This reversible fluorescence switching upon the pH stimuli could be explained by virtue of the protonation and/or deprotonation. When the acid was added, the amine groups from the oligoaniline and triphenylamine segments should be protonated, which would readily change the ring torsional angle and interchain interaction, and then possibly eliminate some pathway of fluorescence quenching, thereby leading to an enhanced fluorescence behavior ('on' state). After addition of alkaline substance, the deprotonation would bring about the pathway of fluorescence quenching, and then the fluorescence decrease to its original state, resulting in the 'off' state. 

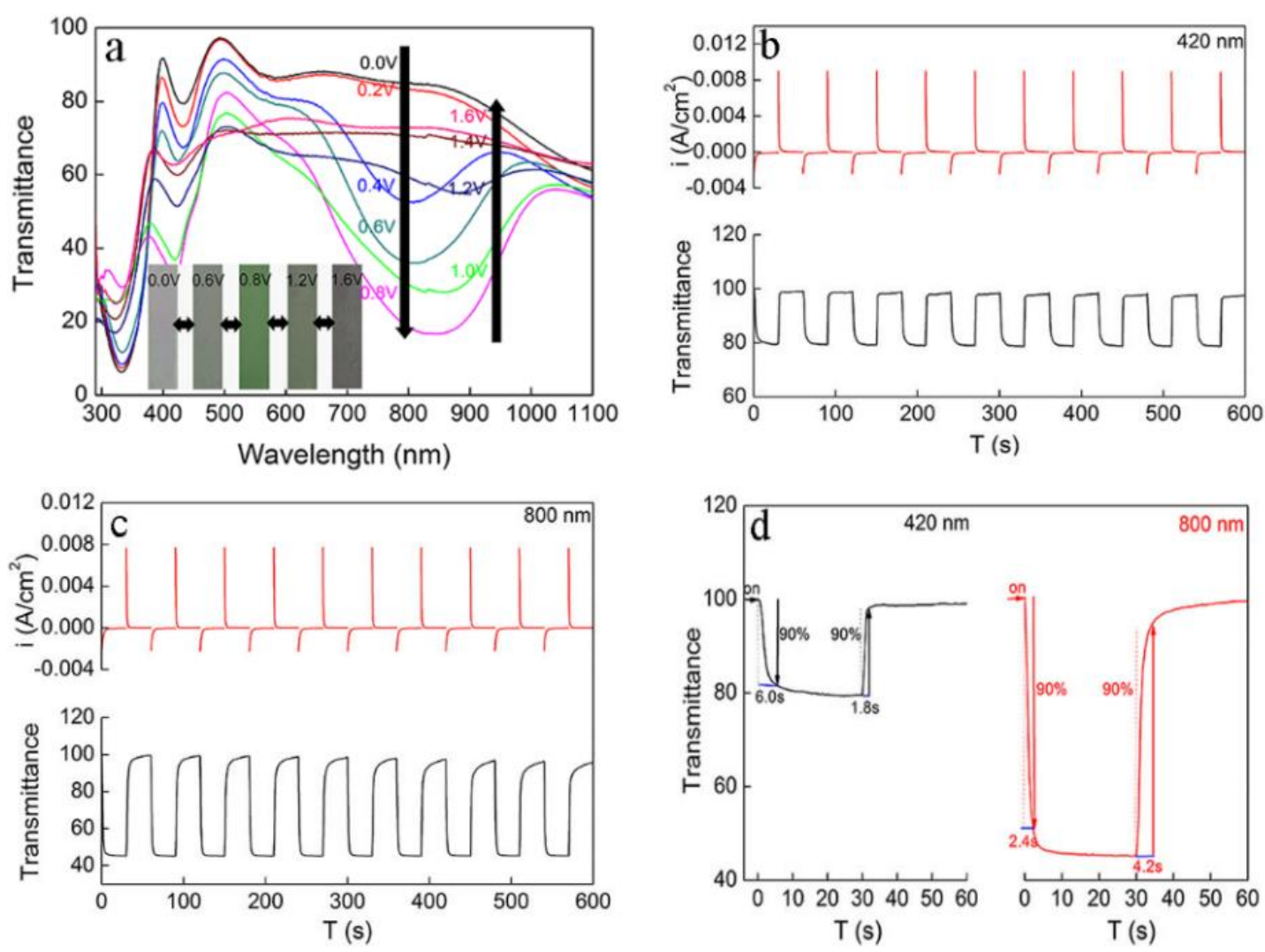

Figure 4. (a) Transmittance spectra of PAAOTF/ITO electrode in $0.1 \mathrm{M} \mathrm{TBAP} / \mathrm{CH}_{3} \mathrm{CN}$ at different potentials $(0.0-1.6 \mathrm{~V})$ with a residence time of $300 \mathrm{~s}$. Inset shows photographs of the PAAOTF at different potentials. Transmittance change and current consumption monitored at (b) $420 \mathrm{~nm}$ and (c) $800 \mathrm{~nm}$ of PAAOTF between $0.0 \mathrm{~V}$ and $0.8 \mathrm{~V}$ with a residence time of $30 \mathrm{~s}$. (D) Switching time of PAAOTF at $420 \mathrm{~nm}$ and $800 \mathrm{~nm}$.

In the light of the electrochemical features of oligoanilines and triphenylamine, the spectroelectrochemical techniques were performed on the PAAOTF/ITO working electrode to evaluate its electrochemical stimuli-responsive spectroscopic behavior. Its electrochromic performance was studied firstly. The transmittance change at various applied potentials from 0.0 $\mathrm{V}$ to $1.6 \mathrm{~V}$ was shown in Figure $4 \mathrm{a}$. The optical contrast value increased at first and then decreased, with a maximum value measured about $70 \%(800 \mathrm{~nm})$ at $0.8 \mathrm{~V}$. In the range of 0.0 - 
$0.8 \mathrm{~V}$, the electrochromic groups are only the oligoanilines, as evidenced from the CV result in Figure 1 . When the applied potential was greater than $0.8 \mathrm{~V}$, the triphenylamine groups were activated. However, optical contrast value underwent a decreasing process from $0.8 \mathrm{~V}$ to $1.8 \mathrm{~V}$. That might be attributed to some energy transfer among these functional groups. Moreover, the color of PAAOTF film changed drastically from gainsboro $(0.0 \mathrm{~V})$, to light gray $(0.6 \mathrm{~V})$, to green $(0.8 \mathrm{~V})$, to dark olive green $(1.2 \mathrm{~V})$, and finally to dimgray (1.6 V) (Inset of Figure 4a). The spectrochronoamperometry was also utilized to monitor the changes in the optical contrast at 420 $\mathrm{nm}$ and $800 \mathrm{~nm}$ during repeated potential stepping between $0.0 \mathrm{~V}$ and $0.8 \mathrm{~V}$ with a residence time of 30 s. Results from the first ten cycles were presented in Figure $4 b$ and $4 c$. For the cycles at $420 \mathrm{~nm}$, PAAOTF film revealed a switching time of $6.0 \mathrm{~s}$ at $0.8 \mathrm{~V}$ for the coloring process and $1.8 \mathrm{~s}$ at $0.0 \mathrm{~V}$ for its bleaching process (Figure $4 \mathrm{~d}$ ). Its corresponding coloration efficiency was calculated about $20 \mathrm{~cm}^{2} / \mathrm{C}$. As for the cycles at $800 \mathrm{~nm}$, PAAOTF film exhibited switching times of $2.4 \mathrm{~s}(0.8 \mathrm{~V}) / 4.2 \mathrm{~s}(0.0 \mathrm{~V})$, and a high coloration efficiency of $81 \mathrm{~cm}^{2} / \mathrm{C}$. All of the parameters indicate that this novel polyamic acid containing two kind of chromic groups shows great potential for using as the electrochromic material. 

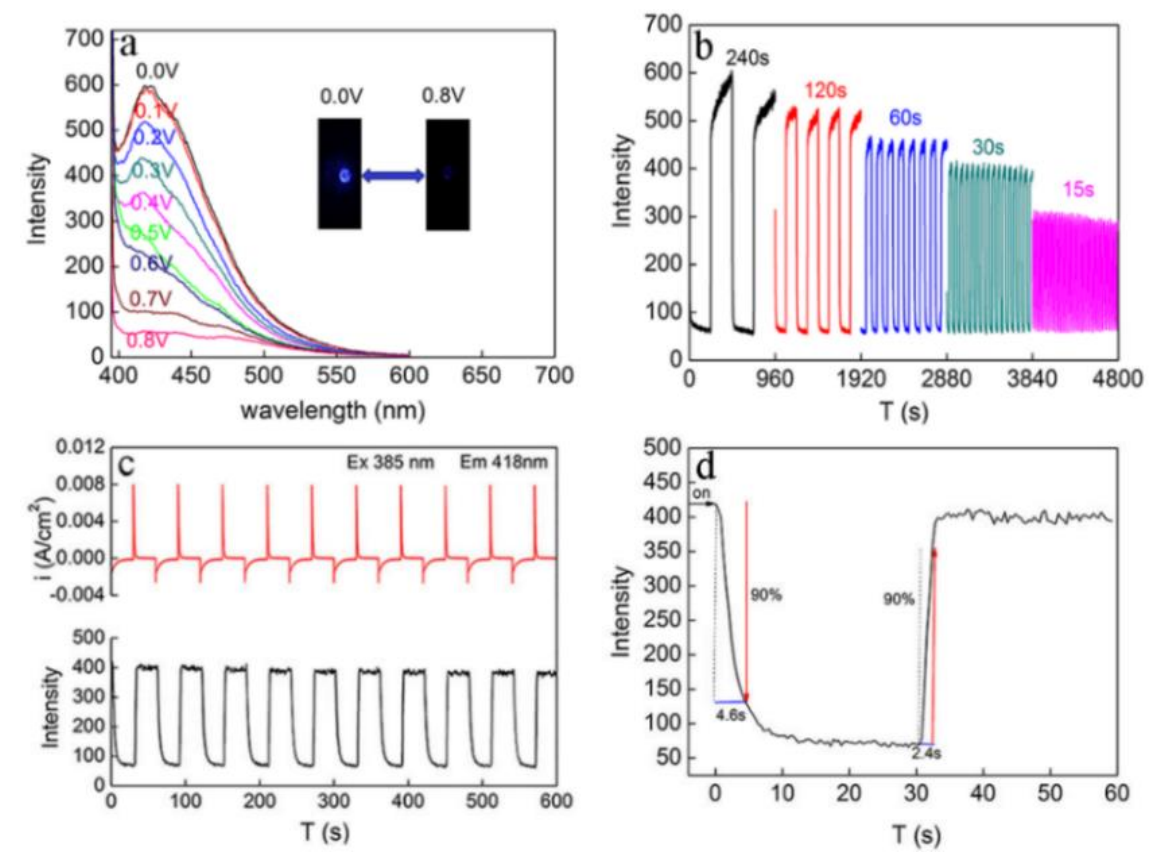

Figure 5. (a) Fluorescence spectra of PAAOTF/ITO electrode in $0.1 \mathrm{M} \mathrm{TBAP} / \mathrm{CH}_{3} \mathrm{CN}$ at different potentials from $0.0 \mathrm{~V}$ to $0.8 \mathrm{~V}$ with a residence time of $300 \mathrm{~s}$. Inset shows photographs of the PAAOTF at $0.0 \mathrm{~V}$ and $0.8 \mathrm{~V}$; excitation wavelength is $385 \mathrm{~nm}$. (b) Fluorescence switching response of PAAOTF under applied step potential $(0.0 \mathrm{~V}$ and $0.8 \mathrm{~V})$ with a residence time of 240, 120, 60, 30, and 15 s. (c) Fluorescence change and current consumption monitored at 418 $\mathrm{nm}$ of PAAOTF between $0.0 \mathrm{~V}$ and $0.8 \mathrm{~V}$ with a residence time of $30 \mathrm{~s}$. (d) Fluorescence switching time of PAAOTF at $418 \mathrm{~nm}$.

The fluorescence switching behavior upon electrochemical stimulus was examined by monitoring its fluorescence intensity at different applied potentials (Figure 5a). When the applied potential increased to $0.8 \mathrm{~V}$, the fluorescence intensity of PAAOTF film at $418 \mathrm{~nm}$ reached minimum value, due to the fluorescence quenching effect upon the quinoid rings of oligoanilines. The corresponding fluorescence images of the films were shown as the inset of the Figure 5a. Moreover, there is a blue shift of $35 \mathrm{~nm}$ compared with that of solution state, ascribed 
to the reduction of conjugated degree in the aggregated PAAOTF film. The reduction of conjugated degree could be caused by the drastic distortion during the aggregation process, due to the unique branched structure of triphenylamine. The fluorescent intensity could also recover to its original values by decreasing potentials as evidenced by spectrochronoamperometry between 0.0-0.8 V. Here, the residence time was fix at 240, 120, 60, 30, and $15 \mathrm{~s}$. As shown in Figure 5b, every residence time could generate a reversible and reproducible fluorescence switching behavior. Longer residence time would result in higher fluorescence switching intensity, which reflected the dynamic characteristics of the electrochemical process. The representative fluorescence change and current consumption of PAAOTF film under $0.0 \mathrm{~V}$ and $0.8 \mathrm{~V}$ with a residence time of $30 \mathrm{~s}$ was shown in Figure 5c. There was no obvious fluorescence decay in the first ten cycles, which should be attributed to the good photostability and electric stability of PAAOTF film. Moreover, PAAOTF film exhibited a quick switching time of $4.6 \mathrm{~s}$ at $0.8 \mathrm{~V}$ for the 'off' process and $2.4 \mathrm{~s}$ at $0.0 \mathrm{~V}$ for the 'on' process (Figure $5 \mathrm{~d}$ ).
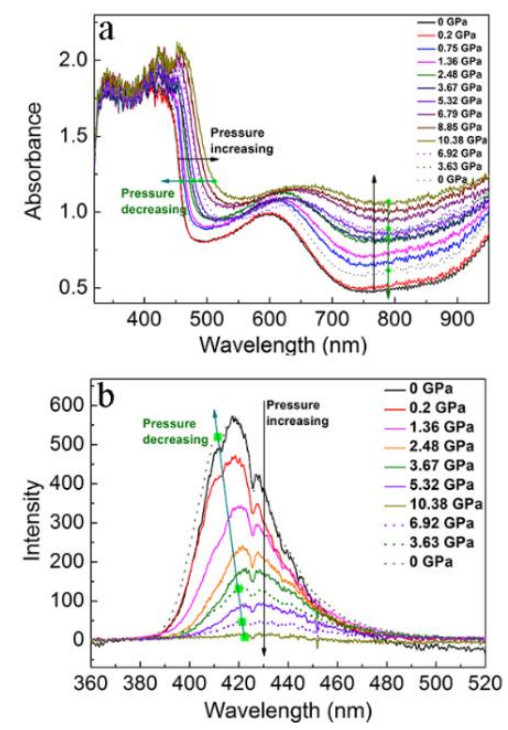

Figure 6. (a) UV-vis absorption spectra and (b) fluorescence spectra of the PAAOTF film with increasing and decreasing pressure. 
In addition, the stimuli-responsive spectroscopic behavior upon the pressure was also investigated through UV-vis absorption spectra and fluorescence spectra, coupled with the diamond anvil cell technique. The quasi-hydrostatic pressure in these optical measurements was applied continually up to $10 \mathrm{GPa}$. Figure 6a illustrated the UV-vis spectra of PAAOTF film with increasing and decreasing pressure. According to its UV-vis absorption spectra with pressure of $0 \mathrm{GPa}$, the free-standing PAAOTF film was considered in the partial oxidative state, ascribed to its oxidation under the air atmosphere during the film-forming process. Pressure-induced red shifts on the absorption edge (from $450 \mathrm{~nm}$ to $500 \mathrm{~nm}$ ) were clearly observed by increasing the pressure from 0 to $10 \mathrm{GPa}$, attributed to an enhancement of the van der Waals interactions by decreasing interchain distances under the increased pressure. After the pressure released to the 0 $\mathrm{GPa}$, the absorption almost recovered to its original value. Meanwhile, the fluorescence variation upon the pressure was also recorded by the fluorescence emission spectra, as shown in Figure $6 \mathrm{~b}$. With pressure increasing, its fluorescence intensity underwent a continual decreasing process. A little red shift from $418 \mathrm{~nm}$ to $429 \mathrm{~nm}$ was also observed, which should be attributed to the reduction of the band gap resulted from the enhancement of the van der Waals interaction under the high pressure. ${ }^{33}$ After releasing the pressure, the fluorescence almost approached its original state. However, minor differences in its optical properties (both UV-vis absorption spectra and fluorescence spectra) were observed for the compressed PAAOTF film, which should be ascribed to the irreversible alteration of free volume of PAAOTF film after the high compression.

\section{CONCLUSIONS}

In conclusion, we have demonstrated a successful design and synthesis of multistimuli polyamic acid bearing oligoaniline, triphenylamine and fluorene groups. The generated 
fluorescence showed a clear multiple stimuli-responsive behavior against redox species, $\mathrm{pH}$, electricity and pressure, contributed by the sensitive oligoaniline and triphenylamine groups. Significantly, via various triggered stimuli, fluorescence modulation and switching of PAAOTF in both solution and film states was realized easily. The interactions between sensitive units and fluorene groups are responsible for the fluorescent switching behavior. Our demonstrated system is expected to enrich the design of stimuli-responsive fluorescent materials and expand their practical applications.

\section{ASSOCIATED CONTENT}

\section{Supporting Information}

The Supporting Information is available free of charge on ACS Publications website at DOI:

FTIR spectrum, ${ }^{1}$ H NMR spectrum, TGA, DTG and DSC curves (PDF)

\section{AUTHOR INFORMATION}

\section{Corresponding Author}

*E-mail: chaodanming@jlu.edu.cn

\section{ORCID}

Danming Chao: 0000-0003-1324-6731

\section{Author Contributions}

The manuscript was written through contributions of all authors. All authors have given approval to the final version of the manuscript.

\section{Notes}

The authors declare no competing financial interest.

\section{ACKNOWLEDGMENTS}


We graciously acknowledge the National Natural Science Foundation of China for funding (grant nos. 21474043 and 11474127).

\section{REFERENCES}

(1) Irie, M.; Fukaminato, T.; Sasaki, T.; Tamai, N.; Kawai, T. Organic Chemistry: A Digital Fluorescent Molecular Photoswitch. Nature 2002, 420, 759-760.

(2) Tian, H.; Yang, S. Recent Progresses on Diarylethene based Photochromic Switches. Chem. Soc. Rev. 2004, 33, 85-97.

(3) Sakai, K.; Tsuchiya, S.; Kikuchi, T.; Akutagawa, T. An ESIPT Fluorophore with a Switchable Intramolecular Hydrogen Bond for Applications in Solid-State Fluorochromism and White Light Generation. J. Mater. Chem. C 2016, 4, 2011-2016.

(4) Che, Y.; Yang, X.; Zang, L. Ultraselective Fluorescent Sensing of $\mathrm{Hg}^{2+}$ through Metal Coordination-Induced Molecular Aggregation. Chem. Commun. 2008, 12, 1413-1415.

(5) Shimizu, M.; Hiyama, T. Organic Fluorophores Exhibiting Highly Efficient Photoluminescence in the Solid State. Chem. Asian. J. 2010, 5, 1516-1531.

(6) Kunzelman, J.; Kinami, M.; Crenshaw, B. R.; Protasiewicz, J. D.; Weder, C. Oligo(pphenylene vinylene)s as a "New" Class of Piezochromic Fluorophores. Adv. Mater. 2008, 20, 119-122.

(7) Hu, L.; Duan, Y.; Xu, Z.; Yuan, J.; Dong, Y.; Han, T. Stimuli-Responsive Fluorophores with Aggregation-Induced Emission: Implication for Dual-Channel Optical Data Storage. $J$. Mater. Chem. C 2016, 4, 5334-5341. 
(8) Ajayaghosh, A.; Chithra, P.; Varghese, R. Self-Assembly of Tripodal Squaraines: CationAssisted Expression of Molecular Chirality and Change from Spherical to Helical Morphology. Angew. Chem. Int. Ed. 2007, 46, 230-233.

(9) Chao, D.; Yang, R.; Jia, X.; Liu, H.; Wang, S.; Wang, C.; Berda, E. B. A Multifunctional Poly(aryl ether) with Oligoaniline and Fluorene Pendants: Synthesis, Electrochromic Performance, and Tunable Fluorescent Properties. J. Polym. Sci. Part A: Polym. Chem. 2012, 50, 2330-2336.

(10) Guo, T.; Deng, Q.; Fang, G.; Yun, Y.; Hu, Y.; Wang, S. A Double Responsive Smart Upconversion Fluorescence Sensing Material for Glycoprotein. Biosens. Bioelectron. 2016, 85, 596-602.

(11) Wang, J.; Yang, G.; Jiang, H.; Zou, G.; Zhang, Q. Photo-responsive CholesterolSubstituted Diacetylenic Organogels: Morphology Tuning, Photo-Switching and PhotoPolymerization. Soft Matter 2013, 9, 9785-9791.

(12) Zhou, C.; Gao, W.; Yang, K.; Xu, L.; Ding, J.; Chen, J.; Liu, M.; Huang, X.; Wang, S.; Wu, H. A Novel Glucose/pH Responsive Low-Molecular-Weight Organogel of Easy Recycling. Langmuir 2013, 29, 13568-13575.

(13) Tropiano, M.; Kilah, N. L.; Morten, M.; Rahman, H.; Davis, J. J.; Beer P. D.; Faulkner, S. Reversible Luminescence Switching of a Redox-Active Ferrocene-Europium Dyad. J. Am. Chem. Soc. 2011, 133, 11847-11849.

(14) Fan, G.; Yan, D. Positional Isomers of Cyanostilbene: Two-Component Molecular Assembly and Multiple-Stimuli Responsive Luminescence. Sci. Rep. 2014, 4, 4933. 
(15) Sun, H.; Liu, S.; Zhao, Q.; Huang, W. Multiple-Stimuli Responsive Luminescent Gels Based on Cholesterol Containing Benzothiadiazole Fluorophores. Chin. J. Chem. 2015, 33, 1140-1144.

(16) Zhao, Y.; Lin, H.; Chen, M.; Yan, D. Niflumic Anion Intercalated Layered Double Hydroxides with Mechano-Induced and Solvent-Responsive Luminescence. Ind. Eng. Chem. Res. 2014, 53, 3140-3147.

(17) Du, X.; Xu, F.; Yuan, M.; Xue, P.; Zhao, L.; Wang, D.; Wang, W.; Tu, Q.; Chen S.; Wang, J. Reversible Luminescence Color Switching in the Crystal Polymorphs of 2,7-Bis(2methyl-[1,1-biphenyl]-4-yl)-fluorenone by Thermal and Mechanical Stimuli. J. Mater. Chem. C 2016, 4, 8724-8730.

(18) Motoyanagi, J.; Ishikawa, T.; Minoda, M. Stimuli-Responsive Brush-Shaped Conjugated Polymers with Pendant Well-Defined Poly(vinyl ether)s. J. Polym. Sci. Part A: Polym. Chem. 2016, 54, 3318-3325.

(19) Wei, Z.; Faul, C. F. Aniline Oligomers-Architecture, Function and New Opportunities for Nanostructured Materials. Macromol. Rapid Commun. 2008, 29, 280-292.

(20) Chao, D.; Jia, X.; Bai, F.; Liu, H.; Cui, L.; Berda, E. B.; Wang, C. An Efficient Fluorescent Sensor for Redox Active Species Based on Novel Poly(aryl ether) containing Electroactive Pendant. J. Mater. Chem. 2012, 22, 3028-3034.

(21) Wang, S.; Berda, E. B.; Lu, X.; Li, X.; Wang, C.; Chao, D. Tuning the Fluorescent Response of a Novel Electroactive Polymer with Multiple Stimuli. Macromol. Rapid Commun. 2013, 34, 1648-1653. 
(22) Shirota, Y. Ultrafast Dynamics of Liquid Poly(ethylene glycol)s and Crown Ethers Studied by Femtosecond Raman-Induced Kerr Effect Spectroscopy. J. Mater. Chem. 2005, 15, 75-93.

(23) Kurosawa, T.; Higashihara, T.; Ueda, M. Polyimide Memory: a Pithy Guideline for Future Applications. Polym. Chem. 2013, 4, 16-30.

(24) Yen, H. J.; Liou, G. S. Solution-Processable Triarylamine-Based Electroactive High Performance Polymers for Anodically Electrochromic Applications. Polym. Chem. 2012, 3, 255264.

(25) Hsiao, S. H.; Lin, S. W. The Electrochemical Fabrication of Electroactive Polymer Films from Diamide- or Diimide-Cored N-Phenylcarbazole Dendrons for Electrochromic Applications. J. Mater. Chem. C 2016, 4, 1271-1280.

(26) Fan, Z.; Li, N.; Quan, Y.; Chen, Q.; Ye, S.; Fan, Q.; Huang, W. Pyrene-Functionalized Oligofluorenes as Non-Doped Deep Blue Emitters for Solution-Processed Organic LightEmitting Diodes. J. Polym. Sci. Part A: Polym. Chem. 2016, 54, 795-801.

(27) Mishra, A.; Fischer, M. K. R.; Bauerle, P. Metal-Free Organic Dyes for Dye-Sensitized Solar Cells: From Structure: Property Relationships to Design Rules. Angew. Chem. Int. Ed. 2009, 48, 2474-2499.

(28) Zhang, G.; Bala, H.; Cheng, Y.; Shi, D.; Lv, X.; Yu, Q.; Wang, P. High Efficiency and Stable Dye-sensitized Solar Cells with An Organic Chromophore Featuring a Binary $\pi$ Conjugated Spacer. Chem. Commun. 2009, 16, 2198-2200. 
(29) Guo, T.; Yu, L.; Zhao, B.; Ying, L.; Wu, H.; Yang, W.; Cao, Y. Blue Light-Emitting Hyperbranched Polymers using Fluorene-co-Dibenzothiophene-S,S-Dioxide as Branches. $J$. Polym. Sci. Part A: Polym. Chem. 2015, 53, 1043-1051.

(30) Sun, N.; Meng, S.; Chao, D.; Zhou, Z.; Du, Y.; Wang, D.; Zhao, X.; Zhou, H.; Chen, C. Highly Stable Electrochromic and Electrofluorescent Dual-Switching Polyamide Containing Bis(diphenylamino)-Fluorene Moieties. Polym. Chem. 2016, 7, 6055-6063.

(31) Jia, X.; Chao, D.; Liu, H.; He, L.; Zheng, T.; Bian, X.; Wang, C. Synthesis and Properties of Novel Electroactive Poly(amic acid) and Polyimide Copolymers bearing Pendant Oligoaniline Groups. Polym. Chem. 2011, 2, 1300-1306.

(32) Sun, N.; Feng, F.; Wang, D.; Zhou, Z.; Guan, Y.; Dang, G.; Zhou, H.; Chen, C.; Zhao, X. Novel Polyamides with Fluorene-Based Triphenylamine: Electrofluorescence and Electrochromic Properties. RSC Adv. 2015, 5, 88181-88190.

(33) Wang, J.; Zhao, X.; Berda, E. B.; Chen, C.; Wang, K.; Chen, S.; Zou, B.; Liu, B.; Zhou, Q.; Li, F.; Chao, D. The Elastic Properties and Piezochromism of Polyimide Films under High Pressure. Polymer 2016, 90, 1-8.

(34) Ohmura, S. D.; Moriuchi, T.; Hirao, T. Chirality Organization of Aniline Oligomers through Hydrogen Bonds of Amino Acid Moieties. J. Org. Chem. 2010, 75, 7909-7912.

(35) Shacklette, L. W.; Wolf, J. F.; Gould, S.; Baughman, R. H. Structure and Properties of Polyaniline as Modeled by Single-Crystal Oligomers. J. Chem. Phys. 1988, 88, 3955-3961. 


\section{Table of Contents}

A multiple stimuli-responsive fluorescent polyamic acid, bearing oligoaniline, triphenylamine and fluorene groups as the sensitive and fluorescence emission unit, is synthesized. The fluorescence switching behavior was studied thoroughly, triggered by redox species, $\mathrm{pH}$, electrochemical and pressure stimuli. This work may provide insight into designing the next generation fluorescent sensing materials coupled with desired stimuli.

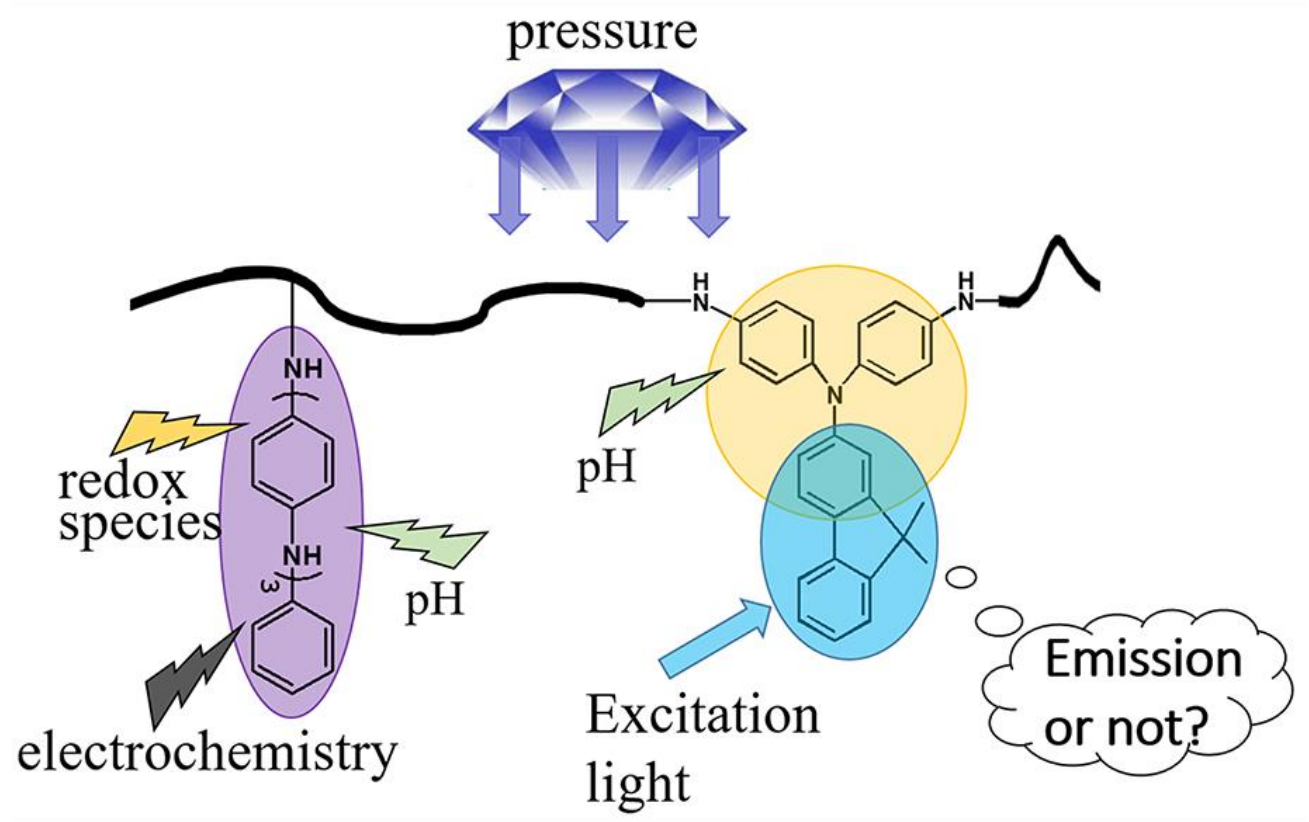




\section{Supporting Information}

\section{Multiple Stimuli-Responsive Fluorescence Behavior of Novel Polyamic Acid bearing Oligoaniline, Triphenylamine and Fluorene Groups}

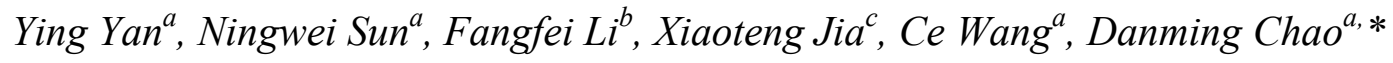

a Alan G. MacDiarmid Institute, College of Chemistry, Jilin University, Changchun, 130012, P.R.

China. E-mail: chaodanming@jlu.edu.cn (D Chao), Tel.: +86-431-85168292; Fax: +86-43185168292.

${ }^{\mathrm{b}}$ State Key Lab of Superhard Materials, Jilin University, Changchun 130012, P.R. China.

${ }^{\mathrm{c}}$ Intelligent Polymer Research Institute, AIIM Faculty, University of Wollongong, Wollongong, NSW 2522, Australia. 


\section{Supporting Figures}

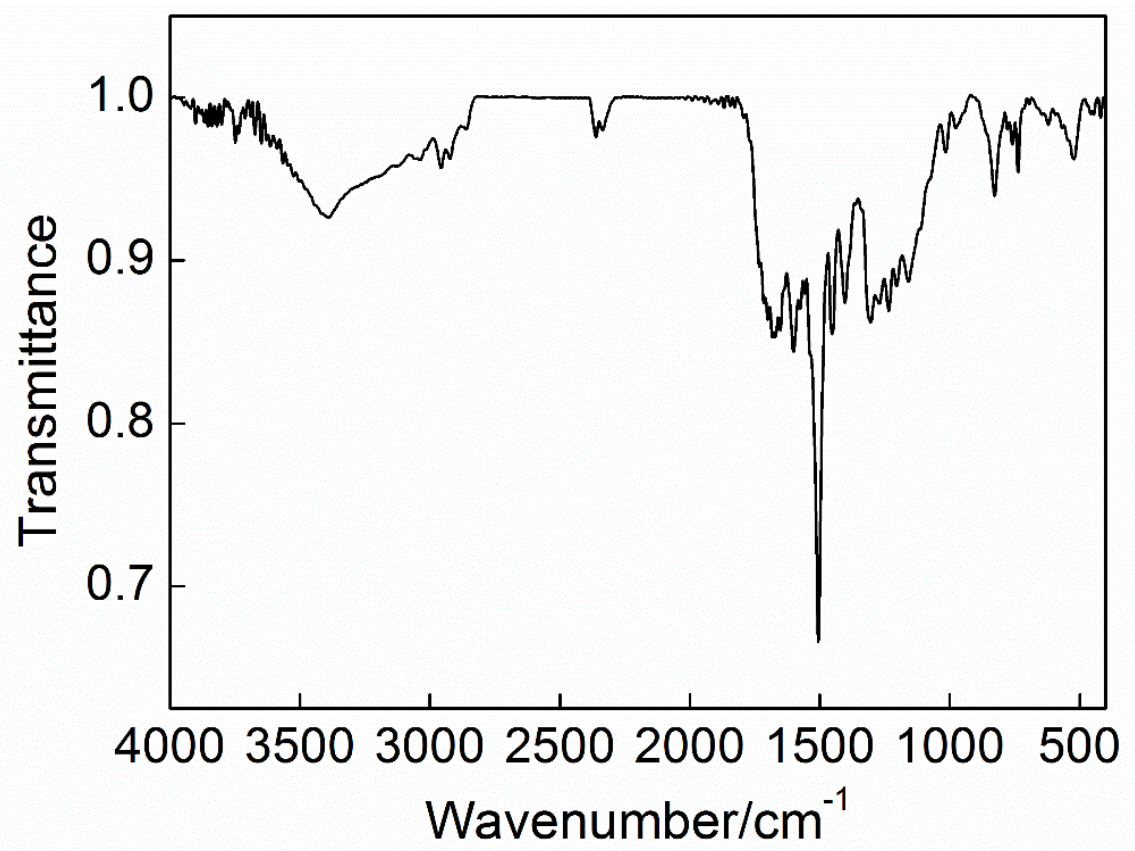

Figure S1. FTIR spectrum of PAAOTF. 


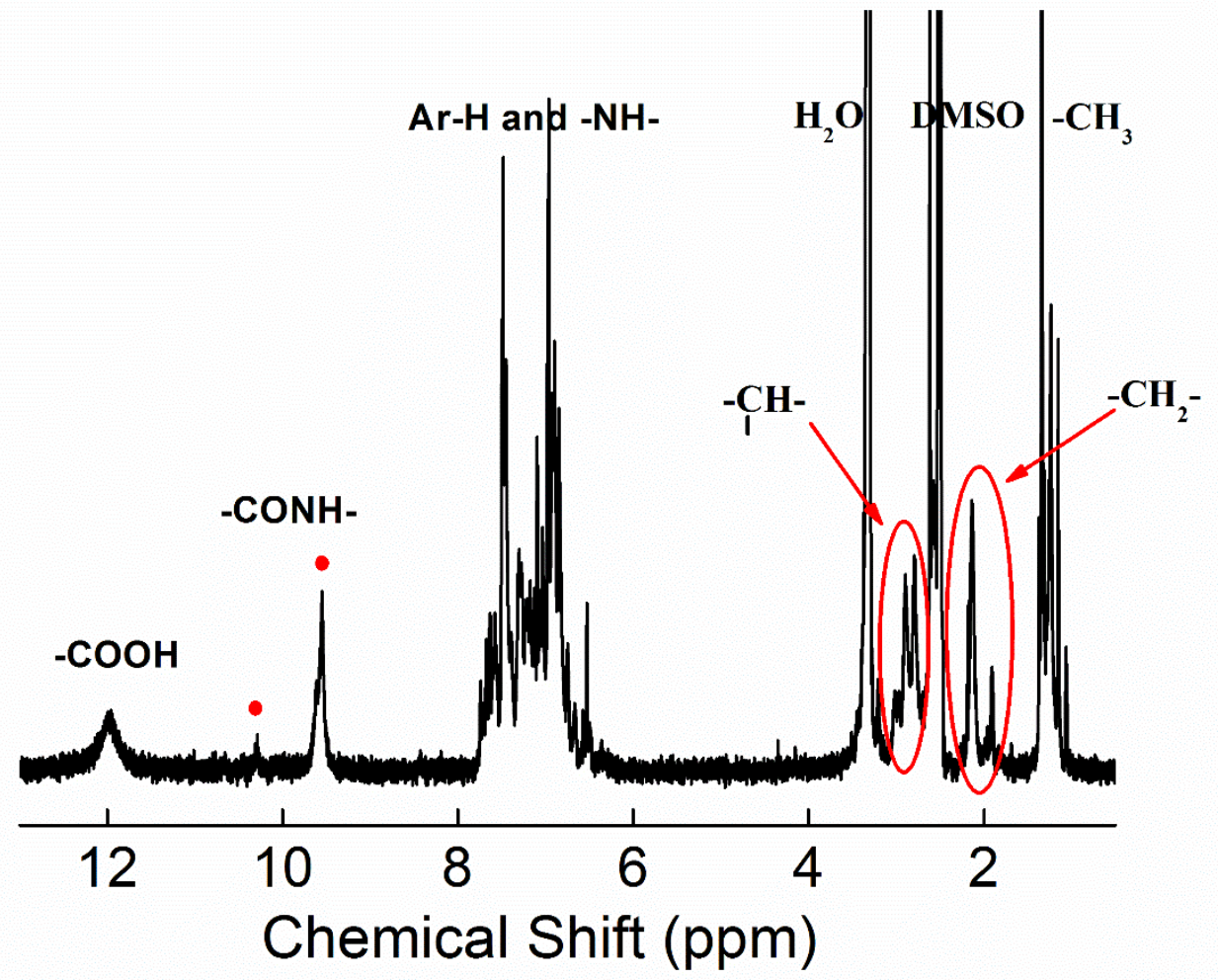

Figure S2. ${ }^{1} \mathrm{H}$ NMR spectrum of PAAOTF. 


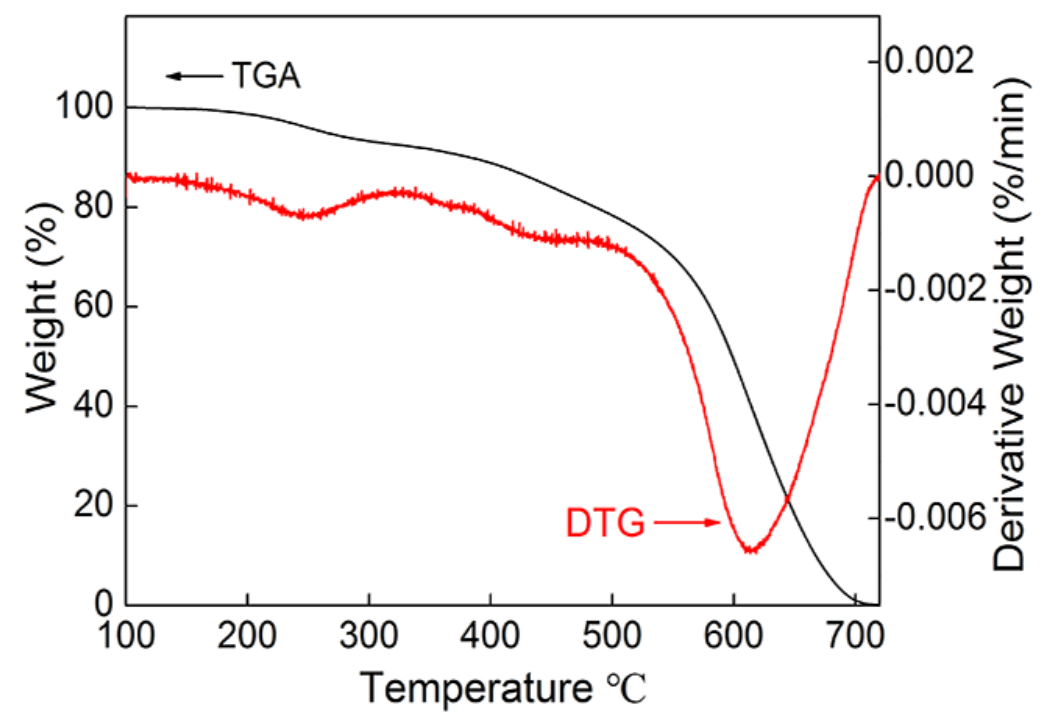

Figure S3. TGA and DTG curve of PAAOTF under air atmosphere. 


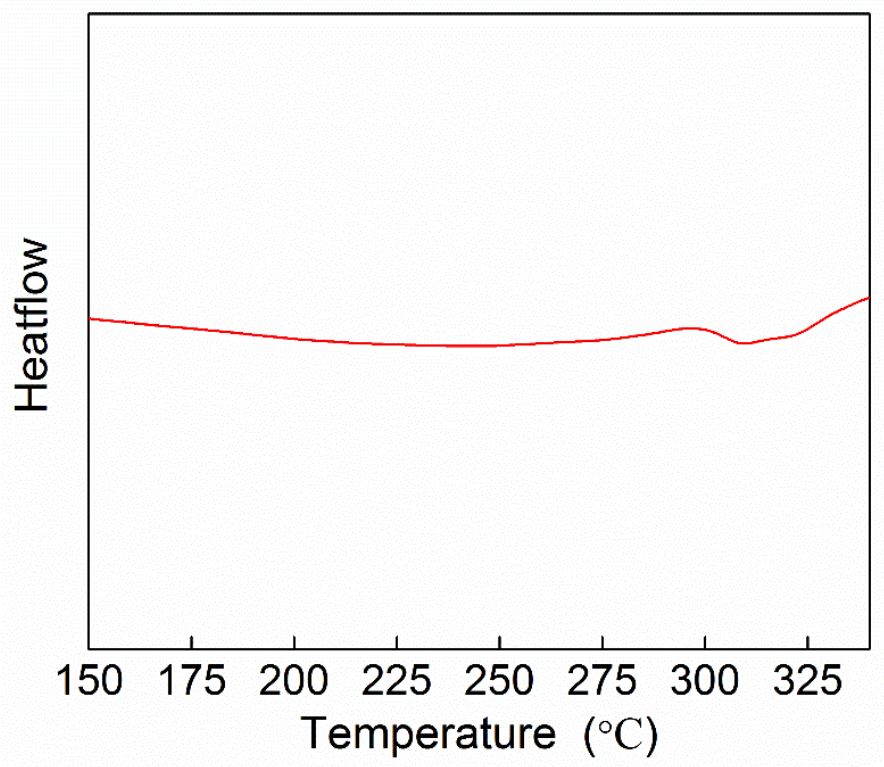

Figure S4. DSC curve of polyimide derived from PAAOTF. 